\title{
Erratum to: Interactions of molten salts with cathode products in the FFC Cambridge Process
}

\author{
George Z. Chen ${ }^{1,2)}$
}

1) Department of Chemical and Environmental Engineering, Faculty of Engineering, University of Nottingham, Nottingham NG7 $2 R D$, UK

2) Department of Chemical and Environmental Engineering, Faculty of Science and Engineering, University of Nottingham Ningbo China, Ningbo 315100 , China

Erratum to: International Journal of Minerals, Metallurgy and Materials

Volume 27, Number 12, November 2018, Page 1572

https://doi.org/10.1007/s12613-020-2202-1

The copyright information of the print version for this article unfortunately is not the same with that of the online version. The copyright information of the online version is right, which is “C The Author(s) 2020".

The online version of the original article can be found at https://doi.org/10.1007/s12613-020-2202-1 